XX Міжнародний симпозіум «Методи дискретних особливостей в задачах математичної фізики/Discrete Singularities Methods in Mathematical Physics», МДОЗМФ/DSMMPh-2021

УДК 539.376

MSC 62P10

\title{
Single-channel processing of auscultatory signals using methods of mathematical morphology
}

\author{
A.G. Rudnitskii A.G., M.A. Rudnytska, L.V. Tkachenko
}

Institute of hydromechanics NASU, Kyiv, Ukraine

E-mail: lusia.tkch@gmail.com

\begin{abstract}
The paper considers a new method of separating respiratory sounds from heart sounds in a general signal registered on the surface of the human body. The proposed approach is based on a combination of Bayesian noise suppression techniques and methods of mathematical morphology. The proposed method was tested on real auscultatory signals. Evaluation of the efficiency of the algorithm using auditory, visual and numerical analysis shows that the developed approach is a promising alternative to existing techniques for separating auscultatory signals into its natural components.
\end{abstract}

Key words: digital auscultation, noise suppression, mathematical morphology, Bayesian theorem.

\section{Одноканальна обробка аускультативних сигналів 3 використанням методів математичної морфології \\ О.Г. Рудницький, М.О. Рудницька, Л.В. Ткаченко Інститут гідромеханіки НАНУ, м. Київ, Україна \\ E-mail: lusia.tkch@gmail.com}

\begin{abstract}
У роботі розглядається нова методика відокремлення звуків дихання від звуків серця у загальному сигналі, зареєстрованому на поверхні людського тіла. Пропонований підхід заснований на комбінації байссівської техніки придушення шумової перешкоди та методах математичної морфології. Запропонований метод був апробований на реальних аускультативних сигналах. Оцінка ефективності алгоритму за допомогою слухового, візуального та чисельного аналізу показує, що розроблений підхід є перспективною альтернативою існуючим технікам розділення аускультативних сигналів на його природні компоненти.
\end{abstract}

Ключові слова: цифрова аускультація, придушення шуму, теорема Байєса, математична морфологія.

\section{1. Введення}

Аускультація, тобто прослуховування і інтерпретація дихальних, серцевих або абдомінальних звуків на поверхні тіла за допомогою стетоскопа, є відомим методом діагностики внутрішніх органів ще $з$ античних часів. Завдяки своїй доступності, простоті та неінвазивності цей метод залишається одним з найбільш поширених способів, що використовуються лікарями, перш ніж звертатися до дорожчих і сучасніших медичних обстежень і тестів. Широкі можливості, які надає комп'ютерна обробка медико-біологічної інформації, дозволили створити нову область аускультації - цифрову аускультацію 3 «розумними» електронними стетоскопами і діагностичними комп'ютерними комплексами. Поряд з розширенням діагностичної потужності таких систем, при їх розробці виникає і низка проблем, зокрема, проблема усунення (зниження) шуму в корисному сигналі, що реєструється на грудній стінці людини. 
Щоб реалізувати переваги комп’ютерної аускультації, загальний сигнал слід розділити на його природні складові: дихальні шуми, звуки серця і стаціонарні фонові шуми. На сьогоднішній день існує ряд підходів до розв'язання цього питання [13]. У даній роботі для розділення аускультативного сигналу на його природні складові використовується комбінований підхід, заснований на методах математичної морфології (ММ) [4] і байєсівській оцінці шумової перешкоди.

Робота організована таким чином. У розділі 2 буде надано короткий опис методів, які використовувалися в розробленому нами алгоритмі. У розділі 3 описано результати застосування комбінації цих методів до розділення реальних аускультативних сигналів на звуки дихання і звуки серця. Завершується стаття обговоренням результатів і можливостей методу

\section{2. Опис методу}

\section{1. Байєсівский метод отримання оптимальної оцінки}

Оскільки досліджуваний аускультативний сигнал нестаціонарний за своєю природою, його обробку доцільно проводити, використовуючи віконне перетворення Фур'є (Short Time Fourier Transform: STFT), з віконної функцією, що переміщується вздовж сигналу у часі. При цьому, часовий інтервал сигналу розділяється на підінтервали, і перетворення Фур'є виконується послідовно для кожного підінтервала окремо. Такий перехід до частотно-часового представлення сигналу дозволяє враховувати і аналізувати його нестаціонарні особливості.

Нехай сигнал $x(t)$ спотворюється некорельованим з ним адитивним шумом $d(t)$, тоді зашумленний сигнал $y(t)$ може бути представлений у вигляді:

$$
y(t)=x(t)+d(t) .
$$

У цьому випадку для частотної області буде справедливий вираз:

$$
Y(\omega)=X(\omega)+D(\omega)
$$

де $Y(\omega), X(\omega), D(\omega)$ - відповідні спектральні образи сигналів $y(t), x(t), d(t)$. У межах підінтервалу віконного перетворення Фур'є останній вираз запишеться у вигляді:

$$
Y(t, \omega)=X(t, \omega)+D(t, \omega)
$$

Тоді задача шумозаглушення може бути сформульована як отримання оптимальної за деяким критерієм оцінки сигналу $x(t)$ по спостережуваному зашумленому сигналу $y(t)$. Відповідно, у STFT-області, ставиться завдання отримання оптимальної оцінки $\hat{X}(t, \omega)$ сигналу $X(t, \omega)$ по відомим значенням сигналу $Y(t, \omega)$.

Згідно до байєсівського підходу, ставиться задача оцінювання спектральних компонент чистого сигналу $X(t, \omega)$ як функції спектральних компонент його зашумленої версії $Y(t, \omega)$ (змінні $t$ і $\omega$ надалі для простоти запису не відмічаються). Для цього визначається дистанція (цільова функція) між значеннями $X(t, \omega)$ i їх оцінкою $\hat{X}(t, \omega)=\hat{X}(Y)$, після чого мінімізується ризик $\mathfrak{R}$, який визначається, як математичне очікування обраної цільової функції [5]:

$$
\mathfrak{R}=E\{C(X, \hat{X})\}=\iint C(X, \hat{X}) f_{X Y}(X, Y) d X d Y,
$$

де символ $E$ означає математичне очікування, $C(X, Y) \geq 0$ - цільова функція, а $f_{X Y}(X, Y)$ сумісна щільність ймовірності величин $X$ та $Y$.

Тоді байєсівська оцінка $\hat{X}(t, \omega)$ знаходиться з виразу: 
XX Міжнародний симпозіум «Методи дискретних особливостей в задачах математичної фізики/Discrete Singularities Methods in Mathematical Physics»,

МДОЗМФ/DSMМРh-2021

$$
\hat{X}(t, \omega)=\underset{\hat{X}}{\arg \min }\left\{\int C(X, \hat{X}) f_{X / Y}(X / Y) d X\right\} .
$$

Очевидно, що для розв'язання цієї задачі необхідно, по-перше, визначитися 3 видом цільової функції для обчислення подібності між чистим сигналом і його оцінкою, i, по-друге, слід вибрати статистичну модель, що описує оброблювані сигнали.

За умови: $C(X, \hat{X})=(|X|-|\hat{X}|)^{2}$ для оцінки амплітудного спектра маємо $|\hat{X}|_{\text {MмSE }}=G \cdot|Y|$, де $G$ - функція корекції спектра мінімальної середньоквадратичної помилки віконного амплітудного спектра (MMSE-STSA) має вигляд [6]:

$$
G=\frac{\sqrt{\pi v_{k}}}{2 \gamma_{k}} \exp \left(\frac{-v_{k}}{2}\right)\left[\left(1+v_{k}\right) I_{0}\left(\frac{v_{k}}{2}\right)+v_{k} I_{1}\left(\frac{v_{k}}{2}\right)\right] .
$$

Тут $I_{0}(\cdot)$ і $I_{1}(\cdot)$ - модифіковані функції Бесселя нульового і першого порядку, $v_{k}=\frac{\xi_{k}}{1+\xi_{k}} \gamma_{k}, \xi_{k}=\frac{\sigma_{X, k}^{2}}{\sigma_{D, k}^{2}}, \gamma_{k}=\frac{\left|Y_{k}\right|^{2}}{\sigma_{D, k}^{2}}, \sigma_{X, k}^{2}=E\left\{|X|^{2}\right\}, \sigma_{D, k}^{2}=E\left\{|D|^{2}\right\}$, а індекс $k$ означає частотну смугу спектра.

Зауважимо, що функція корекції спектра при цьому залежить лише від $\gamma_{k} \mathrm{i} \xi_{k}$, а функції щільності розподілу величин $X$ і $D$ вважаються гаусовими 3 нульовим математичним очікуванням.

Існує багато підходів до їх визначення [6]. У пропонованій роботі використовується підхід, заснований на застосуванні методів математичної морфології.

\section{2. Математична морфологія}

Спектрограма звукового сигналу може розглядатися як двовимірне зображення. Тому алгоритми обробки і шумозаглушення, призначені для обробки зображень, можна застосувати і до задачі обробки звукових сигналів. На такому двовимірному акустичному образі аускультативного сигналу ясно розрізняються ділянки, що відповідають дихальним шумам і звукам серця. Зокрема, області спектрограми, які відповідають звукам серця, на зображенні виглядають, як періодично повторювані вертикальні лінії підвищеної інтенсивності (Рис.1).
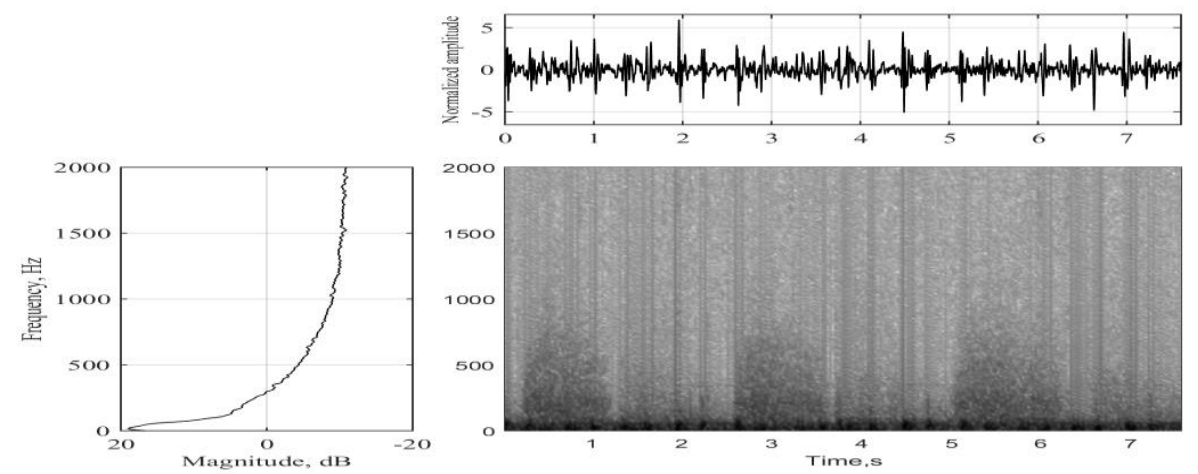

Рис.1. Спектрограма типового аускультативного сигналу при швидкості потоку 1 л/хв.

Оскільки всі адитивні компоненти спектра потужності аускультативного сигналу невід'ємні, природно припустити, що нижня огинаюча поверхні спектрогра- 
ми в просторі час-частота-інтенсивність після видалення на ній ділянок, відповідних звукам серця, буде відповідати спектру потужності дихальних і фонових шумів. Для реалізації цієї процедури були застосовані методи математичної морфологіï.

Математична морфологія - це розділ математики, що охоплює такі математичні дисципліни як топологія, теорія множин, випадкові функції і теорія решіток. ММ аналізує просторові об'єкти, їх структуру, форму та границі. 3 самого початку цей метод в основному застосовується для аналізу та обробки зображень. Техніка обробки полягає у порівнянні об'єкта, що аналізується (зображення), з іншим пробним об'єктом відомої форми, який називається структуруючим елементом. Він може мати різні форми та розміри (диск, лінія, хрест, багатокутник і т.п.). Вибір структуруючого елемента залежить від особливостей зображення, що аналізується, і є вирішальним для успіху обробки. Основні морфологічні фільтри базуються на операціях морфологічного розмикання та закриття [7].

При цьому операція розмикання для напівтонових зображень використовується для видалення невеликих у порівнянні з примітивом світлих ділянок, так що після цього ці області зливаються з фоном. Аналогічно, операція закриття вилучає з напівтонового зображення темні деталі, які не співпадають із структуруючим елементом, а залишок адаптує до фону.

\section{3. Обробка}

Ефективність розробленого алгоритму перевірялась на реальних аускультативних сигналах, отриманих в експериментах, описаних у роботі [8]. При цьому, двоканальна реєстрація аускультативних сигналів здійснювалась контактними п'єзоелектричними акселерометрами. Датчики розміщувались на рівні другого міжребер'я спереду (середньо-ключична лінія) симетрично на лівій і правій верхніх ділянках легенів. Пацієнти підтримувати дихання із швидкістю потоку 0,5 та 1 л/с протягом 4-5 циклів дихання для кожного з режимів. Було отримано аускультативні записи 16 добровольців у віці 10-26 років (3 жінки та 13 чоловіків). Записані сигнали були посилені, відфільтровані в діапазоні 7-4000 Гц і відцифровані із частотою дискретизації 8000 Гц.

Спектрограми сигналів розраховувались шляхом застосування дискретного STFT до кожних 100 мс сегменту даних з 25\% перекриттям між сусідніми сегментами із застосуванням вікна Ханінга (Hanning). На Рис.1 спектрограма сигналу відображена на головній панелі, на верхній панелі зображено сигнал у часовій області, а усереднений спектр цього сигналу розміщено на лівій панелі. Горизонтальна вісь на спектрограмі - це тривалість запису в секундах, вертикальна вісь відображає частотний діапазон. Інтенсивність спектральних компонент відображається у градаціях сірого (білий колір - найнижча інтенсивність, чорний - найвища).

Оскільки серцеві сегменти на спектрограмі - це вертикальні лінії з підвищеною інтенсивністю, алгоритм ММ-фільтрації з лінійним структуруючим елементом повинен надійно розрізняти і вилучати ці ділянки з оригінальної спектрограми. Отже, якщо взяти інфінум від результату такого морфологічного розмикання по всім кутам, то вихідне зображення розділиться на фон, який не включає лінійних елементів, та на частину зображення з лінійними формами. Математично це можна записати у вигляді: 
XX Міжнародний симпозіум «Методи дискретних особливостей в задачах математичної фізики/Discrete Singularities Methods in Mathematical Physics»,

МДОЗМФ/DSMMPh-2021

$$
J_{1}=\inf _{i=1, \ldots N}\left\{\gamma_{B_{i}}\left(J_{0}\right)\right\},
$$

де $B_{i}$ - це структуруючий елемент в $i$-му напрямку, $\gamma$ - операція морфологічного розмикання, а $J_{0}$ - оригінальне зображення. Таким чином отримується апріорна інформація, необхідна для застосування байєсівської процедури, що описана у попередньому розділі.

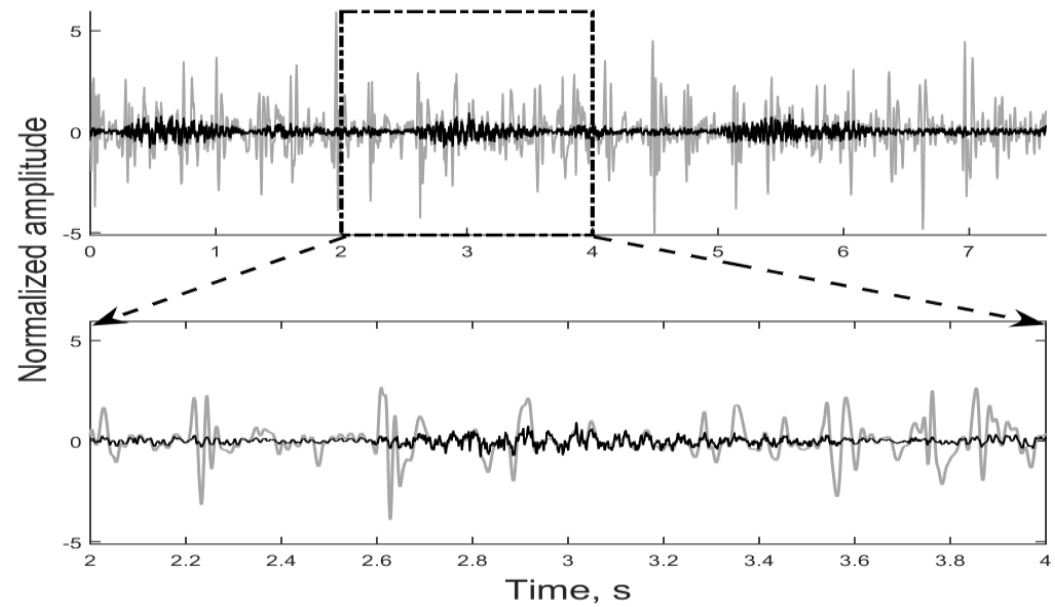

Рис.2. Сигнали, розділені запропонованим алгоритмом (швидкість потоку 1 л/хв.).

Верхня панель: сіра лінія - оригінальний зашумлений сигнал, чорна лінія - оцінка звуків дихання. Нижня панель: сіра ліня - звуки серця, чорна лінія - звуки дихання.

На Рис.2 проілюстровано результат застосування розробленого алгоритму. Збільшений фрагмент містить усі компоненти сигналу: паузу (тишу) між циклами дихання, звуки дихання та серцеві тони.
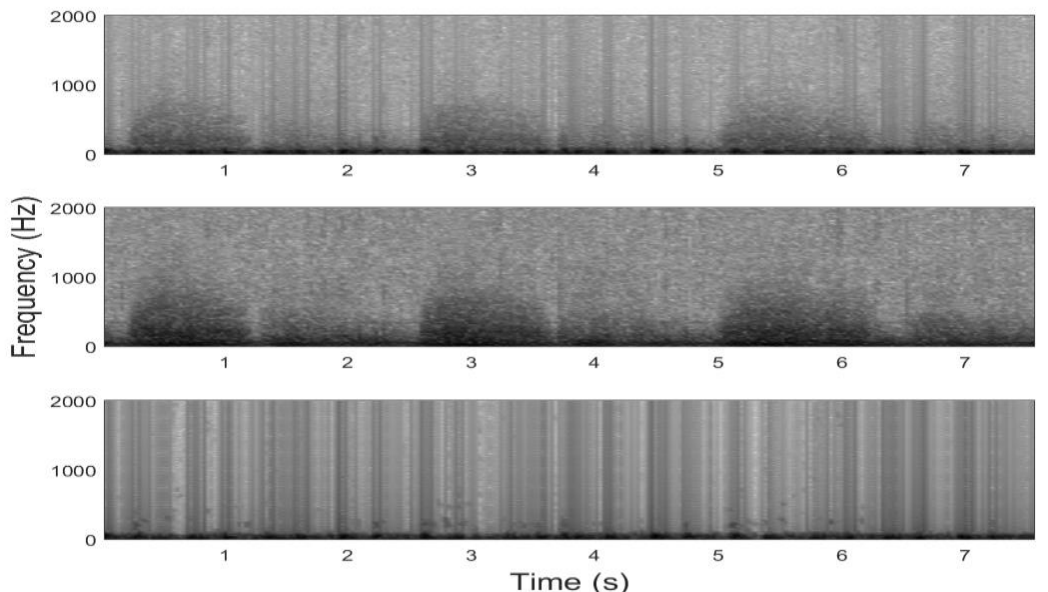

Рис. 3. Спектрограми аускультативного сигналу при швидкості потоку 1 л/хв: верхня панель - оригінальний сигнал; середня панель - спектрограма дихальних шумів; нижня панель - спектрограма оцінки звуків серця. 
Візуальну оцінку ефективності алгоритму можна також зробити і в частотночасовій області - Рис.3.

Оскільки в реальній ситуації чистий сигнал невідомий, кількісна оцінка роботи алгоритму була проведена для кута розбіжності векторів оцінки серцевих звуків та залишку (дихання + фоновий шум). Кут між ними повинен бути близьким до $90^{\circ}$, в силу їх некорельованості. У нашому випадку $\varphi \sim 77^{\circ}$, коли інтенсивність дихання становила близько 0,5 л/хв, і $\varphi \approx 71^{\circ}$ при швидкості потоку 1 л/хв. Як бачимо, кут $\varphi$ приймає значення, досить близькі до $90^{\circ}$ для обох режимів дихання. Відмінність цього кута від $90^{\circ}$, можна пояснити недоліками шумової моделі, що є предметом подальших досліджень.

\section{4. Висновки}

У наданому дослідженні була представлена методологія, яка поєднує математичну морфологію та байєсівський підхід. Запропонована техніка включає два етапи.

На першому кроці спектрограма аускультативного сигналу розкладається на фон та передній план. Цей крок був реалізований із використанням підходу, заснованого на методах математичної морфології. На другому кроці серцеві звуки та шуми дихання були розділені на основі методології байєсівського оцінювання шумової складової.

Ефективність запропонованої техніки оцінювалась суб'єктивно та об'єктивно Суб'єктивна візуальна оцінка результатів роботи запропонованого методу проводилась як у частотно-часовій, так і в часовій області.

Другим інструментом, який було використано для суб'єктивної оцінки методу, був тест на аудіювання. Ця оцінка також підтвердила ефективність запропонованої техніки з точки зору видалення шуму та збереження особливостей сигналу, що цікавить. Кількісний аналіз реконструйованих сигналів показав, що запропонований підхід може ефективно відокремлювати дихальні та серцеві звуки в аускультативному сигналі і може представляти інтерес як для кардіологів, так і для пульмонологів.

\section{ЛІТЕРАТУРА}

1. Rudnitskii A.G. Mathematical morphology approach for single-channel processing of auscultative sound. Journal of Applied Mathematics and Computation. 2019. 3(5), pp. 616-626.

2. Rudnitskii A.G. Two-Channel Processing of Signals for the Separation of Breath and Cardiac Sounds. Acoustical Physics. 2001. 47, N. 3, pp. 353-360.

3. Rudnitskii A.G. Using Nonlocal Means to Separate Cardiac and Respiration Sounds. Acoustical Physics. 2014. Vol. 60. No. 6, pp. 719-726.

4. Matheron G. Random sets and integral geometry. John Wiley \& Sons, New York, 1975.

5. Van Trees H.L. Detection, Estimation and Modulation Theory: Part I. Wiley, 1968.

6. Ephraim Y., Malah D. Speech enhancement using a minimum mean-square error short-time spectral amplitude estimator. IEEE Trans. Acoust., Speech, Signal Process. 1984. Vol. 32, pp. 1109-1121.

7. Heijmans H.J.A.M. Morphological image operators. Advances in electronics and electron physics, supplement. Academic Press, Boston, MA, 1994. 
XX Міжнародний симпозіум «Методи дискретних особливостей в задачах математичної фізики/Discrete Singularities Methods in Mathematical Physics»,

\title{
МДОЗМФ/DSMМPh-2021
}

8. Makarenkov A.P., Rudnitskii A. G. Diagnosis of lung pathologies by two-channel processing of breathing sounds. Acoust. Phys. 1995. 41, pp. 234-238.

\section{Одноканальна обработка аускультативніх сигналов с использованием методов математической морфологии}

\author{
А.Г. Рудницький, М.А. Рудницкая, Л.В. Ткаченко \\ Институт гидромеханики НАНУ, г. Киев, Украина \\ E-mail: lusia.tkch@gmail.com
}

\begin{abstract}
В работе рассматривается новая методика разделения аускультативных сигналов на дыхательные шумы и звуки сердца. Предлагаемый подход основан на комбинации байесовской техники подавления шумовой помехи и методах математической морфологии. Предложенный метод был апробирован на реальных экспериментальных данных. Оценка эффективности алгоритма с помощью слухового, зрительного и численного анализа показывает, что разработанный подход является перспективной альтернативой существующим техникам разделения аускультативных сигналов на его природные компоненты.
\end{abstract}

Ключевые слова: цифровая аускультация, подавление шума, теорема Байеса, математическая морфология. 